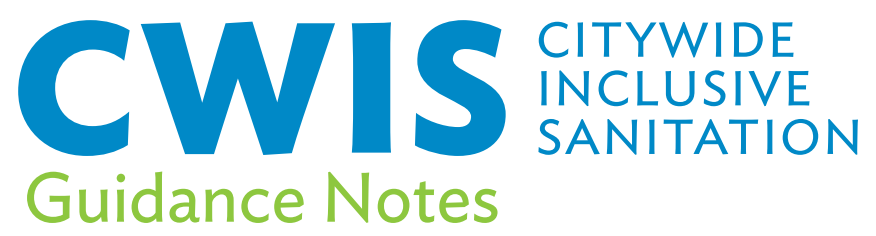

The Citywide Inclusive Sanitation (CWIS) Guidance Notes aim to share essential knowledge to embed CWIS principles in planning and delivering sanitation services to developing member countries of the Asian Development Bank (ADB). These easy-to-understand learning materials are prepared by Water Sector Group of ADB, and structured along the $A D B$ project processing cycle. They can be used to advocate and share the benefits of CWIS to all stakeholders.

\title{
Addressing Gender Equality and Social Inclusion in Urban Sanitation Projects
}

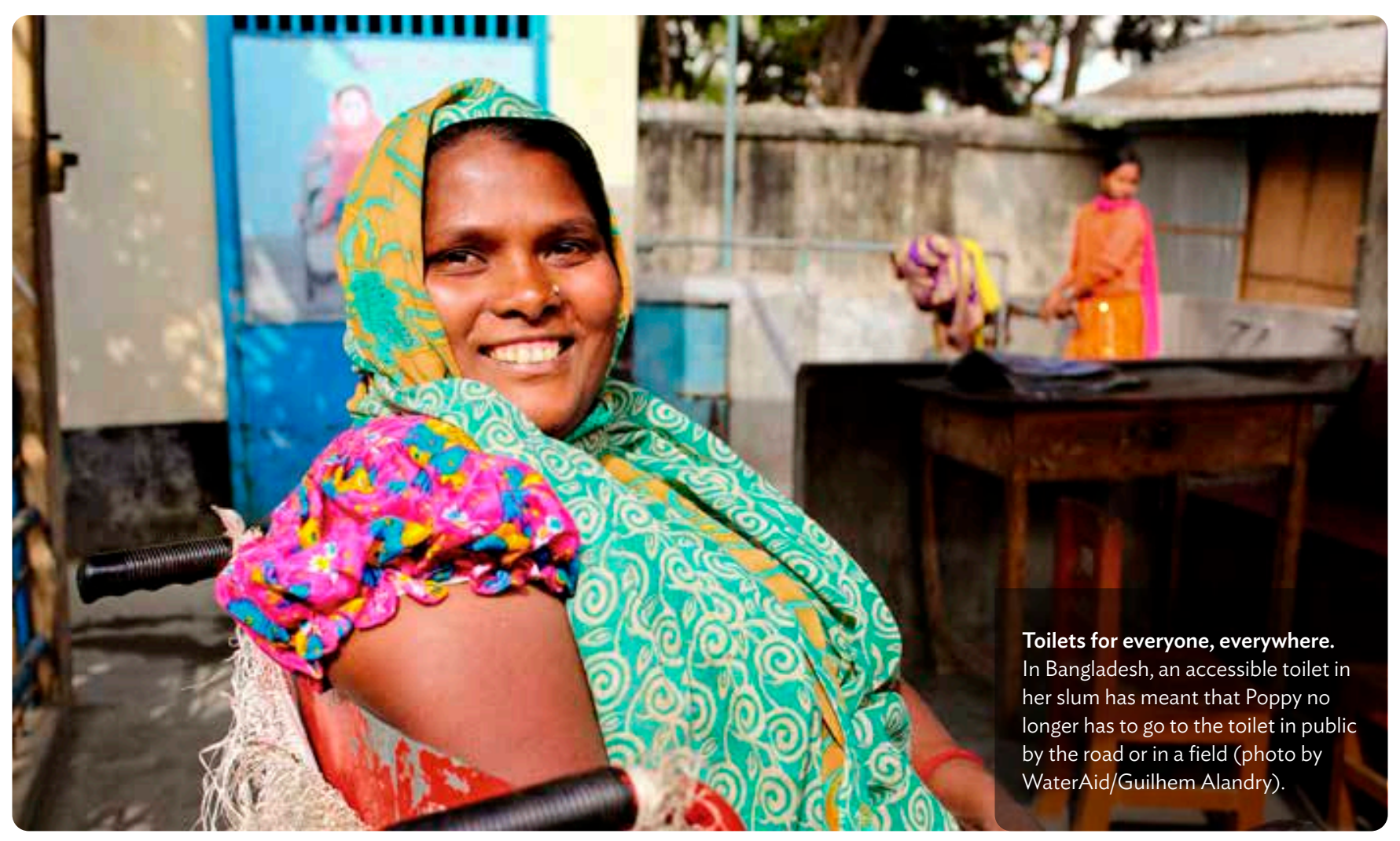

The outcome of a Citywide Inclusive Sanitation (CWIS) approach and supporting investments is that everyone in an urban area gains access to, and benefits from, appropriate and sustainable sanitation services. Reaching everyone does not happen automatically. CWIS projects need activities to target specific unserved and underserved groups. These include women and children, ethnic minorities, urban poor, and persons with disabilities if the CWIS element of equity and inclusion are to be met (Box 1).

This guidance note describes why addressing gender equality and social inclusion (GESI) is fundamental to CWIS project success. It provides some practical suggestions for increasing GESI in projects and five strategies to help deliver these suggestions and achieve sanitation for all. 


\section{BOX 1}

\section{Definitions of Gender Equality and Social Inclusion}

Gender equality refers to the equal rights, responsibilities, and opportunities of women, men, girls, and boys. A gender equality approach requires the interests, needs, and priorities of both women and men to be considered, and recognizes diversity among groups of women and men.
Social inclusion is the process of improving the ability, opportunity, and dignity of people who are disadvantaged based on their gender, race, ethnicity, religion, sexual orientation and gender identity, or disability status, to take part in society.

Sources: UN Women. (2013). Concepts and Definitions. https://www.un.org/womenwatch/osagi/conceptsandefinitions.htm.

World Bank. 2013. Inclusion Matters: The Foundation for Shared Prosperity. New Frontiers of Social Policy. Washington, DC: World Bank. https:// openknowledge.worldbank.org/handle/10986/16195

License: CC BY 3.0 IGO.

\section{What Has Gender Equality and Social Inclusion Got to Do with Sanitation?}

Improving GESI means that the project is designed to benefit everyone in a city or project area, irrespective of their location, gender, social status, or financial capacity. Groups that are usually left out will be included. The groups may be women, children, poor and vulnerable people such as ethnic minorities, persons with disabilities, hard-to-reach populations, and transient or displaced people.

The CWIS focus on equity and inclusion is not a business-as-usual approach to sanitation. Many urban sanitation projects, particularly sewerage projects, have typically benefited the commercial and more affluent areas, which were prioritized due to strategic need and cost-effectiveness. As a result, many communities and marginalized groups lack access to safe sanitation facilities and services. In places where sewerage services exist, there may be other barriers to inclusion such as connection costs or high fees. CWIS projects will have a balance of sewered and non-sewered technologies to ensure all areas and people are served as soon as possible.

Exclusion and inequality come at a high cost. ${ }^{1}$ Without the equal participation of all people, including individuals at risk of exclusion, society has less of an opportunity to reach its full potential in terms of its economy, public health, environment, governance, and cohesion. Crucially, when any population group does not have access to safe sanitation, everyone in the city is exposed to fecally transmitted disease. Inequality and exclusion also affect the quality of life of individuals.

For citywide sanitation, including all groups results in more successful project outcomes: 


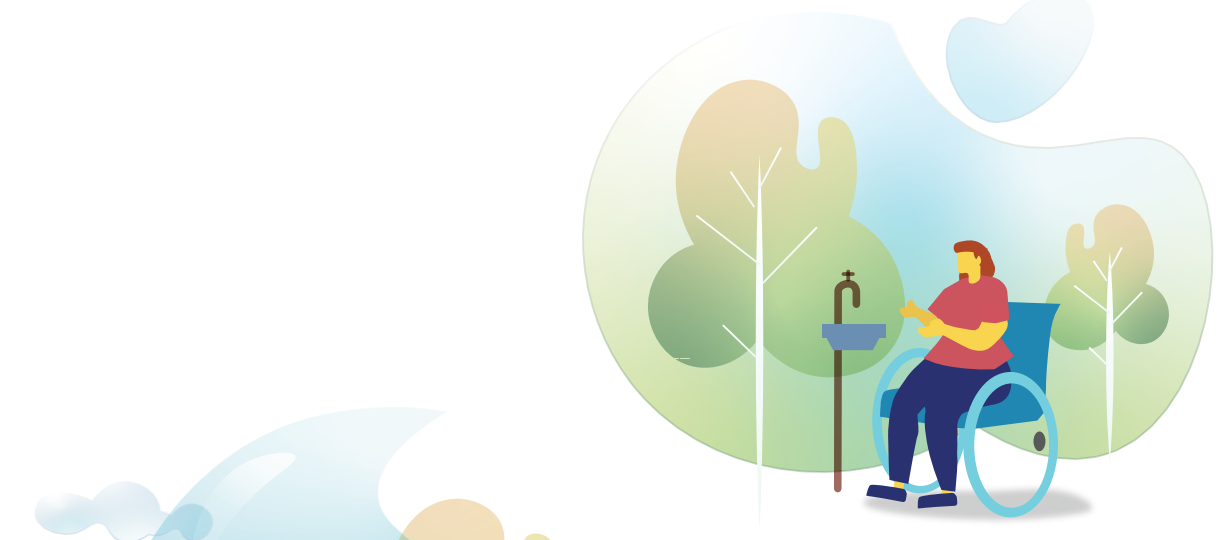

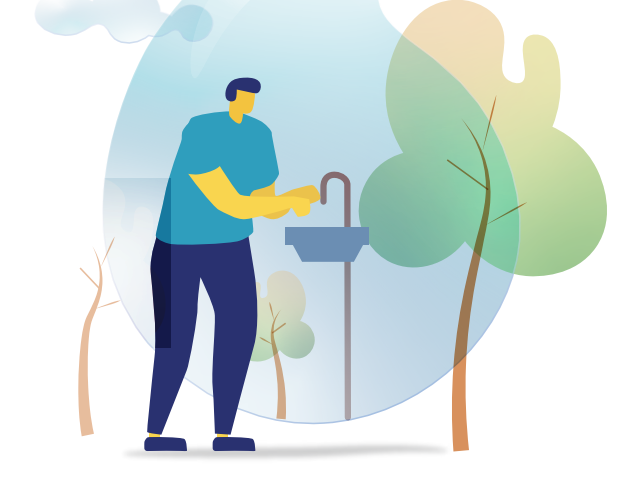

Higher sanitation coverage

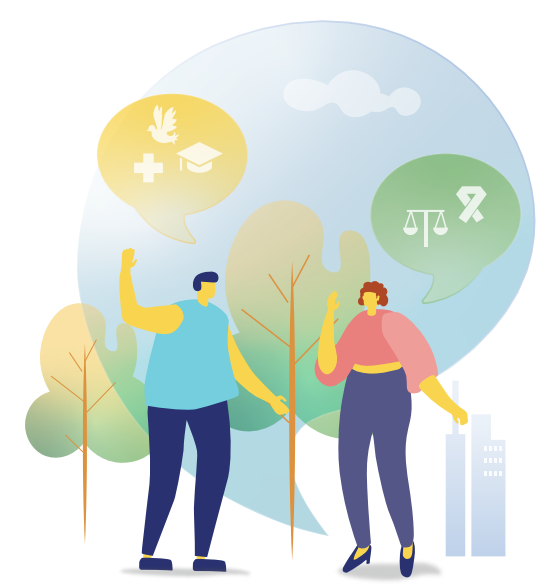

Delivers improved human rights

\section{Meets the sanitation needs} of all users

\section{Good reasons}

for adopting a gender equality and social inclusion (GESI) approach to sanitation.

Including GESI in sanitation projects increases social, health, environmental, and economic benefits.
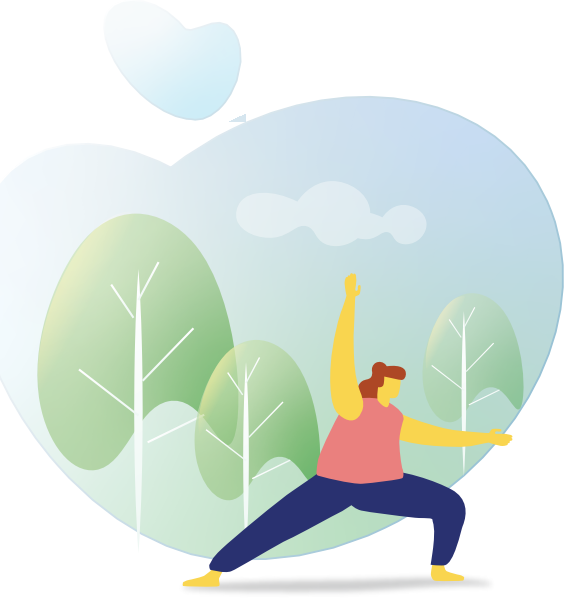

Reduces pollution and improving living environments

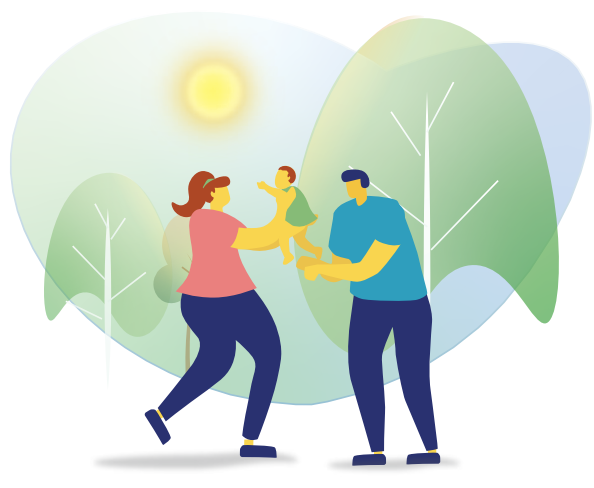

Improves human health

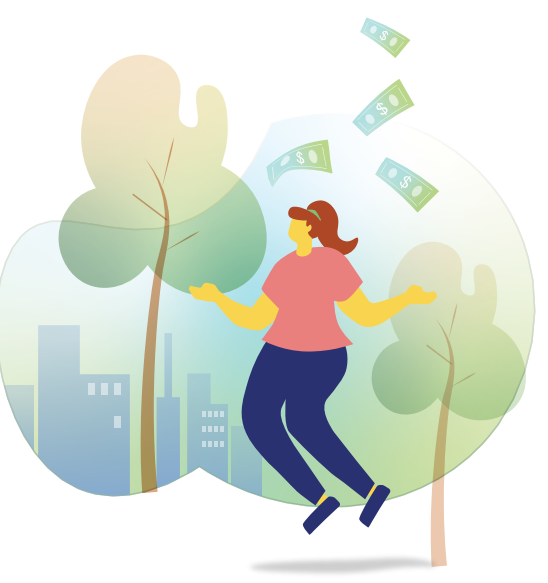

Increases household and city economic prosperity 


\section{How Can Gender Equality and Social Inclusion Be Improved on Citywide Inclusive Sanitation Projects?}

GESI refers not only to ensuring access for all to safe, sustainable sanitation services, but also to addressing the inequalities and exclusionary structures and practices within sanitation policies, institutions, decision-making, capacity development, access to information, and accountability. Practical actions to increase GESI are needed during planning, designing, implementing, and managing sanitation services.
The following suggestions aim to increase GESI in the various components of sanitation projects. How these suggestions are used and integrated will depend on the local context of each project.

\section{Sanitation Planning}

(i) Prioritize sanitation services to unserved households, poor households, or disadvantaged areas within a city. Within this population, prioritize household-level sanitation services as these have the most significant impact on social inclusion. (ii) Where there are existing services, look for ways to connect poor and unserved households to, for example, central wastewater systems. This could be by expanding or rehabilitating the network system and removing their barriers to connection.

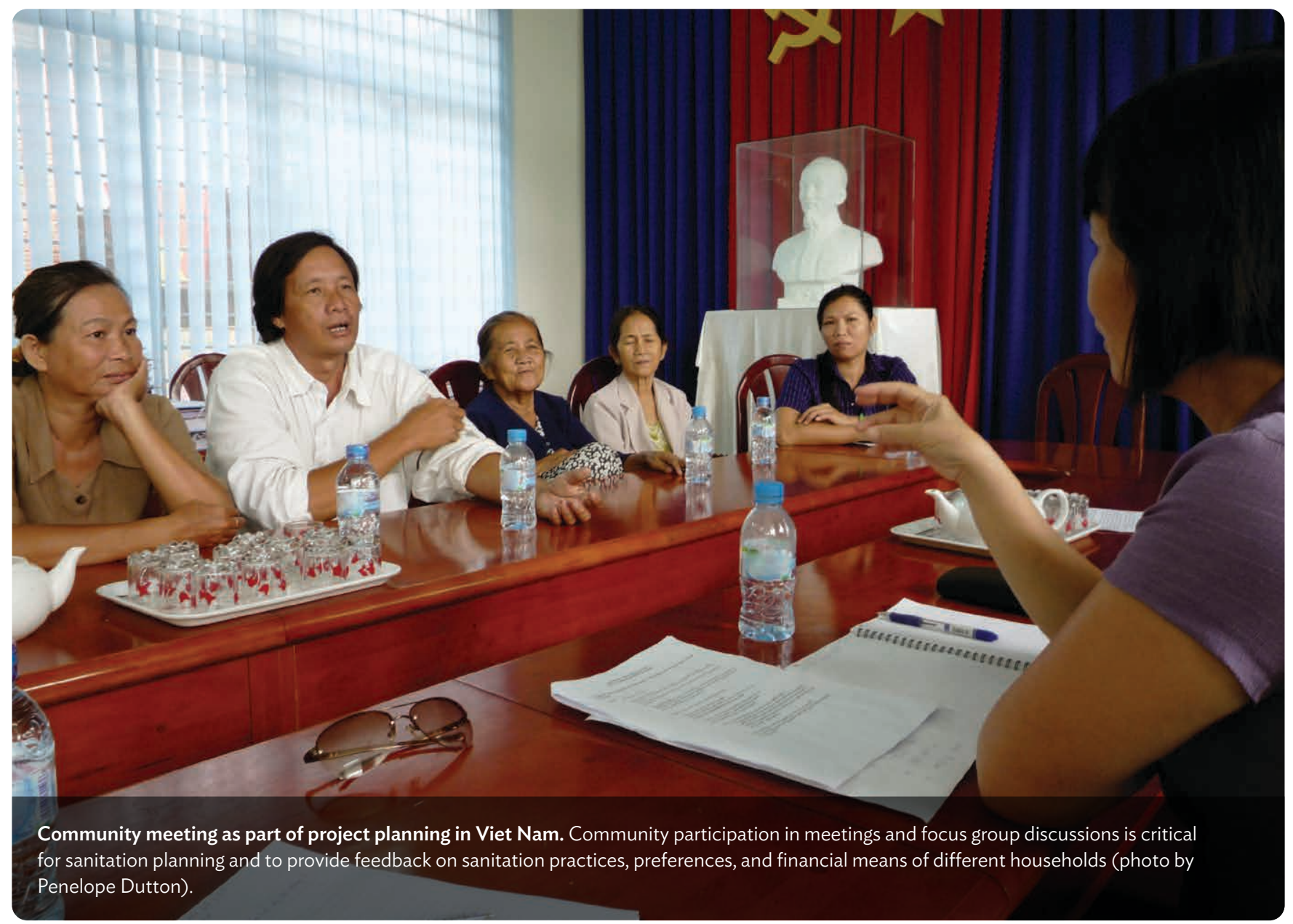


(iii) Identify and quantify poor and disadvantaged communities and individuals to improve project targeting.

(iv) Conduct gender, poverty, and social analysis. This will provide an understanding of cultural practices and perceptions around open defecation, toilet preferences, affordability, menstrual hygiene management, and fecal sludge reuse potential. Analysis can also include the habits and needs of children.

(v) Choose appropriate financial mechanisms to ensure sanitation infrastructure and services are affordable and accessible for the poor and vulnerable.

(vi) Co-design projects with users, using participatory methods that ensure all voices are heard.

(vii) Ensure women and persons with disabilities are consulted on toilet design, especially public or communal facilities.

(viii) Design public or communal sanitation facilities to be female-friendly, child-friendly, and accessible to persons with disabilities. They should be conveniently located and sex-segregated. Also, that they include lighting; are safe, private, and secure; include menstrual hygiene management facilities; and can be easily cleaned. The burden of cleaning often falls on women and people of low status. Access to a reliable water supply is critical for use and cleaning of the sanitation facility.
For more details, see:

- ADB. CWIS Guidance Note on Inclusive Financial Mechanisms: Improving Access to Sanitation Services for Poor Households.

- WaterAid, Water \& Sanitation for the Urban Poor, and UNICEF. 2018. Female-friendly public and community toilets: a guide for planners and decision makers.

- Water \& Sanitation for the Urban Poor. 2014. A gender-inclusive approach in practice: communal sanitation.

- Water \& Sanitation for the Urban Poor. 2011. When are public or communal toilets an appropriate option?

- WaterAid. n.d. The business of a decent toilet: helping women flourish in Bangladesh.

\section{Going further:}

Public or communal sanitation facilities can be even more inclusive if they include bathing and laundry facilities, and offer soap, menstrual hygiene products, and other toiletries for sale.

\section{Sanitation Operation and Maintenance}

(i) Support sanitation workers to (a) be paid properly for the work they do; (b) overcome stigma and social discrimination; and (c) create better working conditions by improving occupational health and safety (including personal protective equipment), establishing standard operating procedures and guidelines, and promoting worker's empowerment through unions and associations. Attractive uniforms can help too.

(ii) Adopt financial mechanisms that make it easier for poor and disadvantaged households to pay the recurring charges for sanitation services, such as desludging and sewerage.

\section{Going further:}

"Sanitation work" includes cleaning public toilets or places around homes and businesses where public defecation occurs; emptying toilets, pits, and septic tanks; entering manholes and sewers to fix or unblock them; transporting fecal waste; operating treatment plants; and disposing of sludge and treated wastewater. 


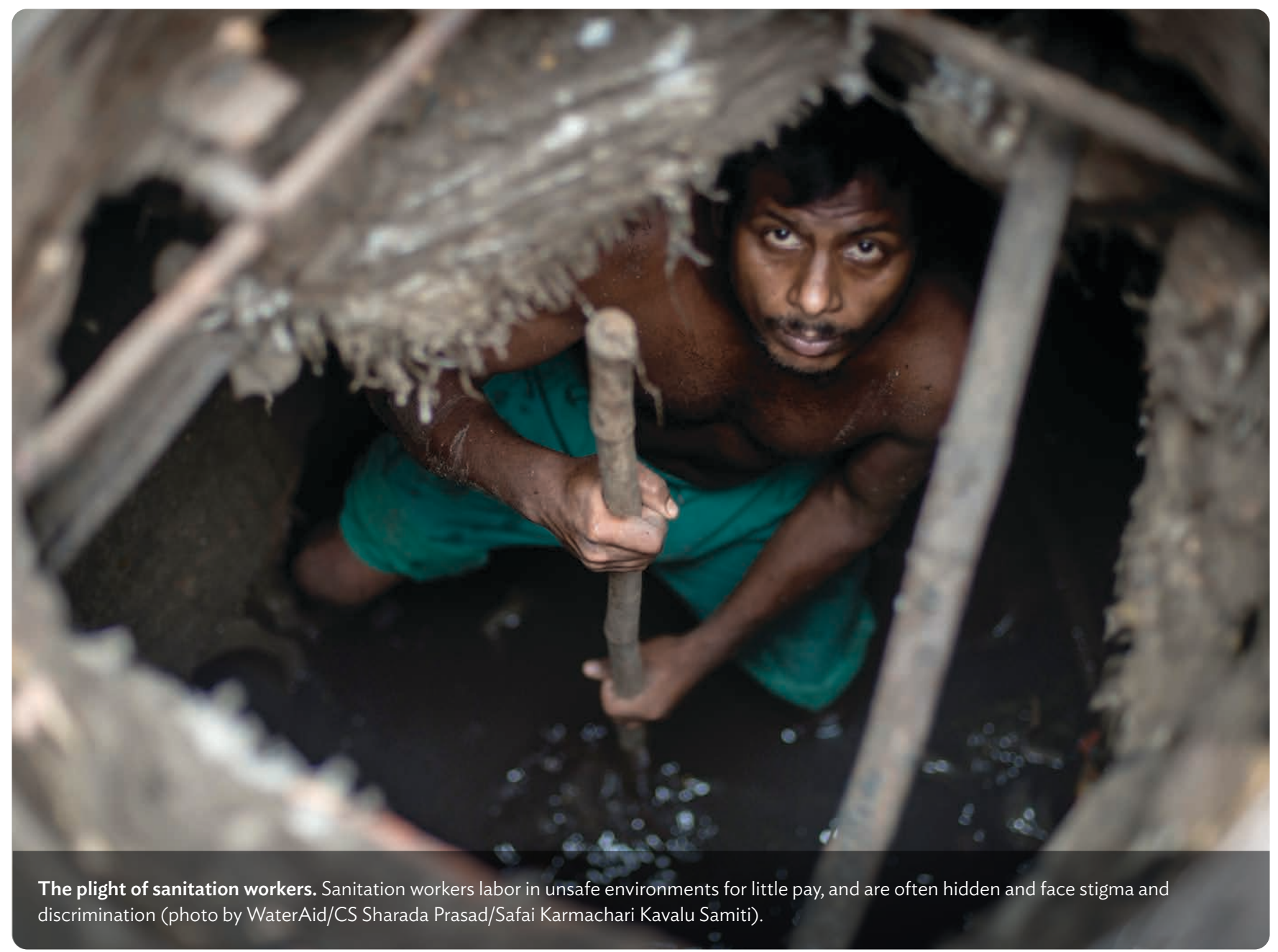

(iii) Strengthen operation, maintenance, and management of public and communal toilets so they provide a safe, appealing, and sustainable sanitation service. Public and communal toilets should be open when needed, clean, operational, and affordable for users.
For more details, see:

- World Bank, International Labour Organization, WaterAid, and World Health Organization. 2019. Health, Safety, and Dignity of Sanitation Workers: An Initial Assessment.

- ADB. CWIS Guidance Notes on Inclusive Financial Mechanisms: Improving Access to Sanitation Services for Poor Households.

\section{Enterprise Development}

(iv) Encourage women to initiate and run sustainable sanitation businesses through incentives, quotas, and information about tenders. Provide opportunities for capacity building, including in business management and contracting. (v) Eliminate barriers and inequities women may face in operating a sanitation business, e.g., right to own property or equipment and ability to obtain loans or credit.

(vi) Foster mutual support of women in sanitation businesses through mentoring, networking opportunities, associations, and recognition awards. 
(vii) Ensure project contractors have gender equality in wages and salaries.

(viii) Provide orientation to sanitation contractors on gender-based violence and sex trafficking.
For more details, see:

- D. Tali. 2018. The all-woman team building and selling toilets in Cambodia. The New Humanitarian. 17 May.

- Dasra India. 2017. A sanitation businesswoman fighting the odds. [Video]. YouTube. 7 September.

\section{Policies, Laws, and Regulations}

(i) Advocate mainstreaming GESI across the sanitation service chain in relevant policies, guidelines, laws, and regulations.

(ii) Remove the legal and administrative boundaries that prevent the urban poor and marginalized from accessing sanitation services. For example, this could mean the service is not conditional on legal residence, nationality, formal rental contracts, or other similar conditions.

(iii) Help draft a GESI guideline for sanitation in urban areas.

(iv) Advocate for menstrual hygiene needs for women of reproductive age.

\section{Going further:}

Advocate for gender beyond binary definitions. For example, ensure consultation with transgender and intersex people and offering third-gender toilets, as in India.

\section{Institutions}

(i) Encourage the appointment of women to sanitation management positions within government ministries, municipal authorities, and utilities (Box 2).

(ii) Set a realistic quota for women in sanitation project planning and decision-making fora, e.g., project management units.

(iii) Establish a GESI unit or focal point in the implementing agency who will be responsible for promoting GESI. They will also be able to influence and link multidisciplinary initiatives, including in future sanitation projects.

(iv) Support a dedicated pro-poor unit, social development unit, or peri-urban department within the sanitation utility or responsible government department. It would mobilize and support low-income unserved communities to access services and financial support.

\section{Going further:}

Women and socially marginalized people may need additional support to attend sanitation-related training, workshops, and consultation meetings, for example, transport, childcare, translation, and support work. Events should be held at a convenient time to optimize attendance. 
(v) Integrate appropriate GESI initiatives into procurement processes such as calling for tenders, proposals, and quotes by including GESI tasks in sanitation terms of reference and specifications, where feasible.

(vi) Establish committees and grievance redress mechanisms to combat sexual and identity-based harassment in sanitation agencies and utilities. (vii) Encourage and possibly mandate the participation of women and vulnerable people in responsible positions on sanitation committees.

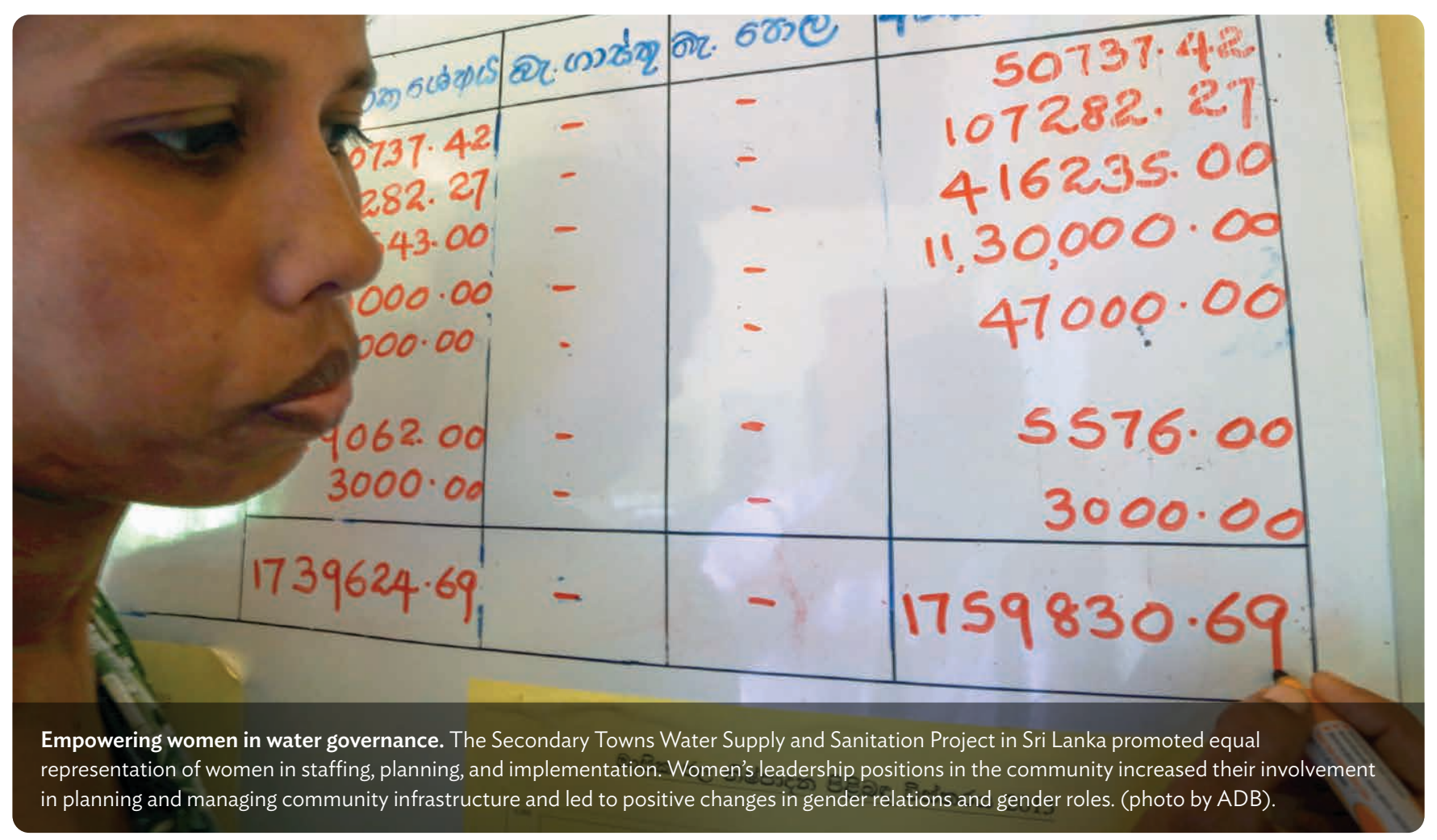

BOX 2

\section{Examples of Gender Equality and Social Inclusion}

Example 1: The Asian Development Bank (ADB) Kolkata Environment Improvement Project included more than 300,000 people living in 85 low-income communities. Staff of the Kolkata Municipal Corporation social development unit, with the help of nongovernment organizations, mobilized the communities, formed self-help groups, and planned and implemented the slum infrastructure improvements. This included going house to house to inform households about the upgrading and sewer connections, resulting in more than 46,000 household connections.
Example 2: In Nepal, water user and sanitation committees (WUSCs) have successfully demonstrated strong community cohesion and leadership, and achieved shared water and sanitation objectives with the Government of Nepal. The ADB Small Towns Water Supply and Sanitation Sector Project mandated 33\% female representation in the WUSCs. Their involvement has strengthened the projects through the women's active participation in technical planning and implementation, while also creating many strong and dedicated women leaders. 


\section{Capacity Development}

(i) Provide GESI and sanitation sensitization training at all levels (including ministries, municipalities, utilities, contractors, community groups, nongovernment organizations [NGOs], and consultants).

(ii) Set requirements for women's participation in capacity development activities and training.

(iii) Allocate quotas for women in apprenticeships, internships, scholarships, or postgraduate qualifications.

(iv) Encourage sanitation consultants to provide opportunities for women and socially disadvantaged people on their teams during project preparation and implementation.

(v) Build the capacity of women's groups and groups representing disadvantaged communities to help them advocate for sanitation services.
For examples and more details, see:

- To promote gender equity, the Rajasthan Secondary Towns Development Sector Project offers internships at a leading government technical institute. This enables at least 500 women to gain professional experience in a technical field.

- The Institute of Technology of Cambodia has developed a Master of Urban Water and Sanitation Engineering program to develop critical skills and support investment loans to the Government of Cambodia for urban water supply and sanitation. To encourage women, the Institute of Technology of Cambodia has included gender in the criteria used for evaluating scholarship applications, which provide financial support (from Agence Française de Developpement and European Union) to 30 students in the program. More women than men have enrolled in the course. After completing the course, students must go back to work in institutions in the sector for 3 years.

\section{Consultation and Communication}

(i) Establish mechanisms throughout the sanitation project cycle which ensure regular and ongoing consultation with women, the poor, and socially excluded people. These groups should be participants, not spectators of sanitation decision-making processes.

(ii) Hold consultation events at times and locations that are convenient for participants, to increase their involvement. Separate meetings for women; the socially excluded; and others who, due to fear or cultural factors, would not speak out in a mixed group.

(iii) Ensure that sanitation consultation events are accessible for people with limited mobility. Ensure they are close to public transport and provide sign language or other language interpreters if members of the community need them.

(iv) Ensure all communication and information (including behavior change communication) use materials and visuals that include a diversity of age, gender, ability, and socioeconomic groups. Ensure these are in the appropriate languages, and employ nonsexist, gender-neutral terminology, and there are options for delivery such as visual and audio. Special outreach mechanisms may be needed for behavior change communications to reach persons with disabilities, especially in cultures where they are usually confined indoors.

(v) Employ both females and males, and representatives from excluded groups as sanitation and hygiene promoters and community mobilizers.

(vi) Promote women as natural change agents and train them in skills to communicate within their household and neighborhood.

(vii) Support female, male, and third-gender people to be GESI change agents in their communities. 


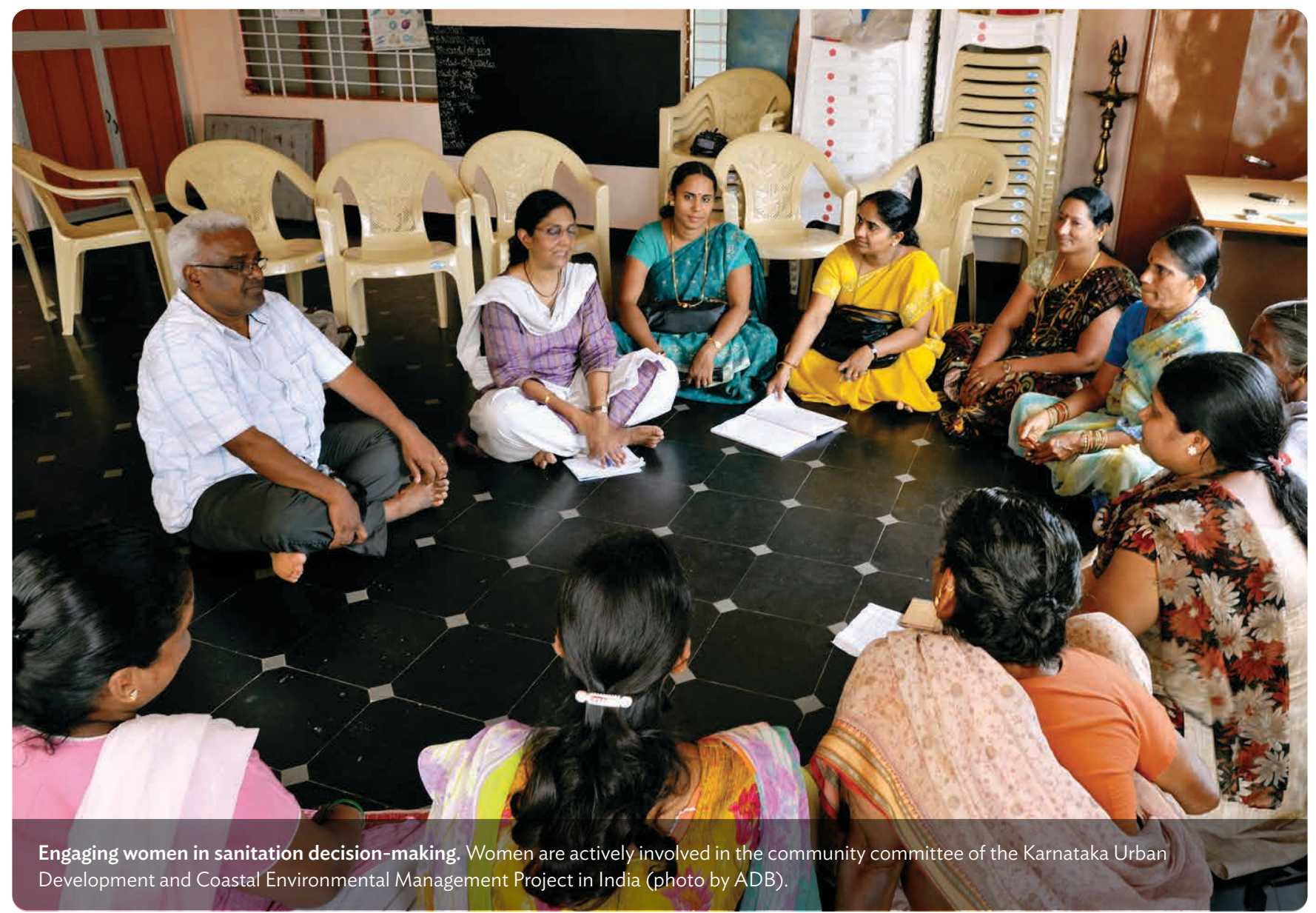

\section{Accountability}

(i) Disaggregate project data by relevant subgroups including women, children, poor households, older people, persons with disabilities, ethnic minorities, and other socially excluded groups. Counting these people reinforces the need to provide services to all.

(ii) Require accountability structures for GESI in sanitation service performance monitoring, e.g., community scorecards, social audits, and utility or agency benchmarking. Excluded groups and representative organizations should participate in the accountability process.

(iii) Improve the capacities of implementing agencies to understand and monitor GESI across the sanitation service chain (infrastructure, services, employment, and business development).

\section{Research}

(i) Allocate a budget for research and adaptive learning on GESI effectiveness during project preparation and implementation. (ii) Conduct research on areas of sanitation where there is limited information about GESI issues. 


\section{Five Strategies to Ensure Gender Equality and Social Inclusion in Citywide Inclusive Sanitation Projects}

The following strategies guide how the practical actions can be embedded in a sanitation project:

\section{Develop gender equality and social inclusion plans.}

Some ADB-financed urban water and sanitation projects are moving beyond gender action plans in their project design to more comprehensive gender and social inclusion plans. These plans put GESI higher on the agenda and mean that social inclusion actions, in addition to gender equality, can be planned and monitored. Some recent examples are from Nepal and India.

- Nepal (NEP 47252): Regional Urban Development Plan

- Nepal (NEP 35173): Urban Water Supply and Sanitation (Sector) Project

- India (IND 42267): Rajasthan Urban Sector

Development Project

- India (IND 42486-018): Madya Pradesh Urban Services Improvement Project

- India (IND49107-006): West Bengal Drinking Water Sector Improvement Project

\section{Partner with and support community- based organizations and/or nongovernment organizations.}

Community-based organizations ( $\mathrm{CBO}$ s) and NGOs can provide an essential link to disadvantaged and marginalized communities and individuals, and often work directly with them. CBOs, such as disabled peoples' associations, can provide specialist advice on inclusion. Local NGOs with a strong grassroots presence in the project area will be more effective at community engagement than NGOs based elsewhere. Assessments should be made of the need for support to strengthen the capacity and experience of $\mathrm{CBOs}$ and $\mathrm{NGOs}$, including the potential for support to come from international NGOs and international experts.

\section{Find GESI champions.}

Developing member countries and implementing agencies can often be unconvinced on GESI actions on sanitation projects. Finding an ally or spokesperson who can use their political capital and power to champion inclusive sanitation will help. These champions could be city leaders, department heads, or members of water and sewerage boards. Identify champions as early as possible and ensure they are of high enough rank to influence others.

\section{Disaggregate data.}

It is much easier to target and track the effectiveness of GESI in sanitation if data are disaggregated by sex, poverty, disability, and ethnicity. This is not always possible, but should be attempted. The information can provide valuable monitoring and learning evidence, but should be reliable and realistic for monitoring.

\section{Budget for GESI initiatives.}

Most of the GESI practical actions for making sanitation more inclusive require a budget. While there is a cost to improving GESI, the results will generate long-term savings, improve sustainability, and provide economic advantages. 


\section{About the Asian Development Bank}

ADB is committed to achieving a prosperous, inclusive, resilient, and sustainable Asia and the Pacific, while sustaining its efforts to eradicate extreme poverty. Established in 1966, it is owned by 68 members -49 from the region. Its main instruments for helping its developing member countries are policy dialogue, loans, equity investments, guarantees, grants, and technical assistance.

Further Reading

ADB Gender Tip Sheets on Gender inclusive projects, preparing and monitoring gender action plans.
Follow us on social media

ff ADBWater

in adb-water

\% adbwater

water@adb.org
(1) Water Secure and Resilient SANITATION FINANCING PARTNERSHIP TRUST FUND BILL \& MELINDA
GATES foundation
- Federal Ministry Republic of Austria Finance

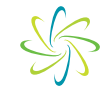

URBAN CLIMATE CHANGE
RESILIENCE RESILIENCE

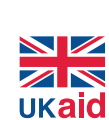

UKaid
Schweizerische Eidgenossenschaft Confédération suisse
Confederazione svizzer Confederazione Svizzera
Confederaziun svizra

Swiss Confederatio

Federal Departement of Economic A

Federal Departement of Economic Affairs,
Education and Research EAER

State Secretariat for Economic Affairs SECO

\section{Contact}

Asian Development Bank

6 ADB Avenue, Mandaluyong City

1550 Metro Manila, Philippines

$+63286324444$

+63286362444

water@adb.org
ISBN 978-92-9269-079-3 (print)

978-92-9269-080-9 (electronic)

Publication Stock No. TIM210393-2

DOI: http://dx.doi.org/10.22617/TIM210393-2 